\section{Mentoring of Media}

\section{Lessons for Tomorrow" The Role of Pre-Production}

\author{
By Linda Bartrom
}

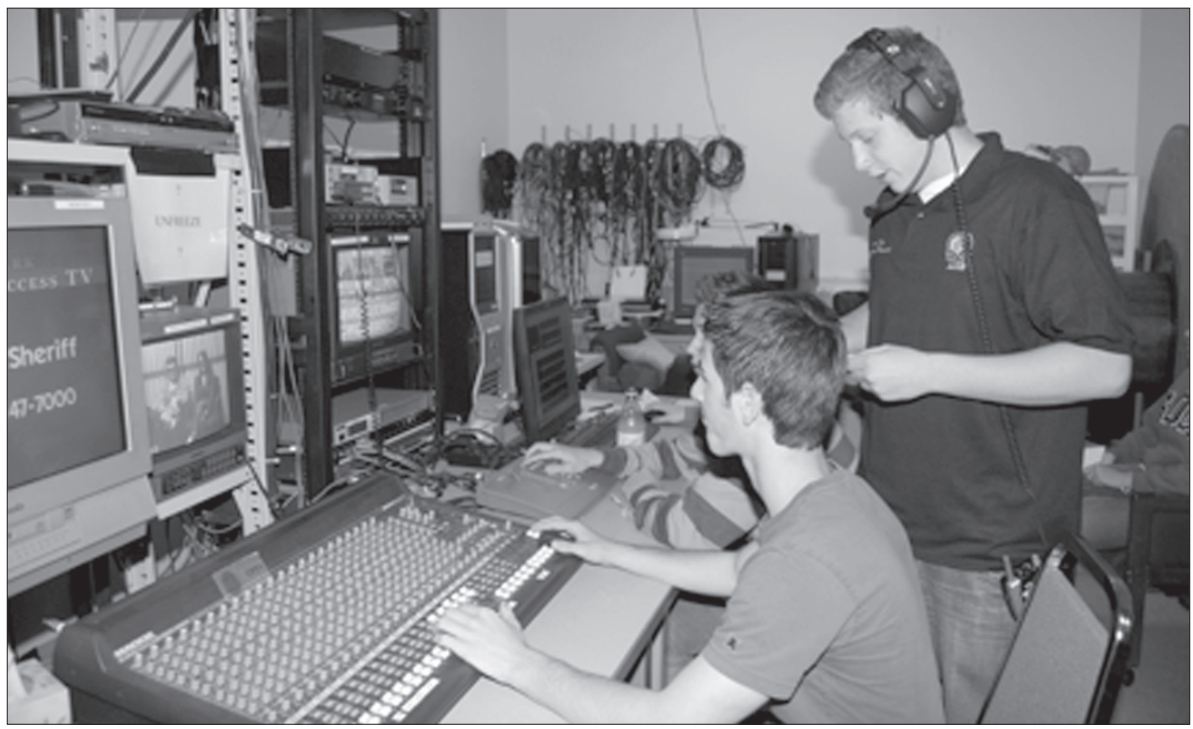

Figure 1. Students in Villa Park High School, California, Television Production Class work as members of the Studio Crew at VPCATV Channel 3: Sound Technician Loren Kaplan, Switcher Blake Edwards and Director Jenson Vliss. Photograph by Jeff Pesner

$\mathbf{P}$ re-production can be the most boring, the most arduous, the most muddled, or the most exciting and enlightening aspect of a production program. Making its value clear to the learner is the deal-breaker here; they have got to know the specific role it holds. Which in turn means that YOU have to know the role it holds. Do you?

Pre-production does far more than produce a script, which at first appears to be its most explicit function. Consider the more important role for the learner in a media class, albeit an implicit one: the assigning of the role each student will play in the production of the end product.

While this may appear to be evident to the onlooker, it is never apparent to the students. Their roles shift due to the need for them to experience all the production jobs, and therefore the explication of their job in that specific show needs to be clear and well-explained before they enter a studio. The overview of the production process belongs to the producer alone... and guess what? That is you. A production is the brain-child of the originator; only you, the instructor, really has a feel for where the production is going to end up; that is the job of a producer, that is the job of the teacher. So what is it that you are supposed to teach students to complete during pre-production?

Well, the script is one obvious component, but casting, hiring as it were, for the production is another, often overlooked component within the context of the classroom. Television production is a composition, a true composite of many jobs, all of which must work together in symphonic harmony; explicating the units in that superstructure clarifies for the student the subdivisions of the composite, and allocates labor for the production itself. Before making a student a Switcher in the control room, make sure all students understand the broader job divi- sion such a specialized role fits into. The major job divisions in television production include Business, Cast, Floor Crew, Studio Crew and Editors.

Business Departments include script development, set design and financial concerns. Cast includes those who appear before the camera on the soundstage, inclusive of (example being a news show): Anchors, Field Reporters and special reporters such as Weathermen and Sports Casters. Floor Crew are those out in the studio executing the technical end of the production including Floor Manager, a Floor Director, Grips, Gaffers and Cameramen. The Studio Crew are the students in the control room who transmit and/or store what is captured from the soundstage including Studio Director, Sound Technician, Switcher and Character Generator. Finally, the Editors are the Postproduction component who remove the captured show from the external hard drive and edit it into a format appropriate to distribution to local stations.

With the next production shift the jobs among your students; encourage them to sample a job from among the families of components. By second semester they will have found which they like best, while having an understanding of, and appreciation for all the other roles. Appreciation of the jobs others do is crucial in something as interdependent as a television production is; it is that very synchronicity which enables the smooth completion of the project. Furthermore, the lesson of pre-production structuring, organizing and assigning jobs, this awareness of the roles played by everyone in an endeavor, reaches far beyond the classroom into life itself. No matter where your learners go or what they become, the great lesson of appreciation for the role others play in the successful completion of the project they are involved in will serve them well. This lesson will have been learned in the long ago of your classroom; some may even remember and return to thank you. Such are the most satisfying moments of an educator's career, and it does happen, it will happen. You are an educator, and you serve far beyond your classroom, you serve the world of tomorrow. For that you will be remembered. 